\title{
On Male Role and Responsibility for Reproductive Health in Africa
}

\author{
Uche Isiugo-Abanihe and Oka Obono \\ Sociology Department \\ University of Ibadan, Ibadan, Nigeria
}

DOI: 10.36108/NJSA/1102/90(0101)

\begin{abstract}
The literature on male role and responsibility for reproductive health in Africa supports the impression that African men are uninterested in the consequences of their reproductive behaviour. This paper argues this view to be inaccurate and historical. The perceived apathy results from the feminization of reproductive knowledge and its confinement to clinical settings, which exclude and alienate men. Men were indeed principal providers of healthcare for their households in the pre-colonial period but were dislodged from this role by the incorporation of their societies into the international labour market, thereby creating working class poverty, and weakening their role in this regard in Nigerian family life. The campaign to involve men in reproductive health programmes should be accompanied by poverty alleviation and family support schemes to mitigate rising costs of modern medical care for themselves, their partners, and their children.
\end{abstract}

Keywords: alienation, feminization, patriarchy, responsibility, ethnomedicine

\section{Introduction}

A substantial part of the reproductive health literature is taken up by interest in male responsibility for safeguarding reproductive health for men, their partners, and children. To a large extent, however, the conclusions about that role are typically negative. They create or support the impression that African men are disinterested in the physical and social consequences of male reproductive motivation and behaviour for their partners and children, as though the evidence truly pointed to this degree of reproductive apathy and social cynicism.

In that body of work, reproductive health is viewed in line with the definition adopted by the International Conference on Population and Development (ICPD) in Cairo, 1994, which in turn followed the preestablished Alma Ata conceptualization of health as a state of complete physical, mental, and social well-being in all matters relating to the reproductive system at all stages of life. The concept (reproductive health) implied that people were able to have satisfying and safe sex lives and had the capability and freedom to decide if, when, and how often to reproduce. Hence, it evinced a fusion of libertarian philosophy and rationalism and required that people have information about, and access to, safe, effective, affordable, and acceptable methods of family planning, and the right to appropriate services that enable women to safely go through pregnancy and childbirth. 
In other words, the scope of reproductive health was fairly broad. It covered topics as diverse as gender, sexuality, and social, economic, emotional, psychological, and ethical questions and rights that are frequently ignored in the human health discourse. Its overlapping dimensions health are rooted in a fundamental patriarchal ethos that assigns differential roles by gender, age, class, and, sometimes, religious precepts - factors that affect people's access to reproductive health services. Such differential access has important implications for maternal morbidity and mortality (Graham et al, 2004), and other reproductive problems. For this reason, the need for more research into inequities in access and utilization of services and information involves a vigorous concern with questions of power, authority, legitimacy, values, social roles, responsibility, and gender.

Before now, scholarly interest in male role and responsibility in reproductive health tended to adopt a slanted or stereotypical view of what that role entailed. It ignored patent variations in it as the male individual progressed through the life course. Thus, it was observed that, "Concerning the stereotypes about male responsibility, much of the literature would suggest that most men fall short of the desired qualities" (SSRHN, 1999: 6). There is inadequate contention with the changes in social positions upon which men's variable roles depend, and how these roles shift with, and are shaped by, the prevailing normative expectations that accrue to these changing patterns and positions. There is even less contention with the range of attitudes and tendencies corresponding to this variety of positions.

The conventional scope of male role in reproductive health is static and fairly limited. It does not include the complex understandings of that role at the community level at large. Rather, it appears restricted to a focus on the family and is based on the assumption that the family is the sole institutional context for understanding reproductive health, as though it is only within it that reproductive rights can be protected. This tendency defines men as heads of households (HHHs), husbands, fathers, and the domestic custodians of patriarchal ideology. The academic literature does not contain as much on male role in other institutional settings as it does within the family system. For this reason, it ends up supposing or demonstrating that role within spousal and parental contexts only, as noted, and this, in our view, is a principal limitation of studies of male role and responsibility.

Both fertility and reproductive responsibility extend far beyond the presumably "natural" settings in which they occur. As an example, homelessness (through, say, internal displacement) does not preclude the discourse of male reproductive responsibility. It makes it even more pertinent. Allusions of this kind make it important to view the construct of "male" through multiple social prisms.

Often, the discourse of male role and responsibility is carried out in the assumption that this refers to adult and, complementarily, marital male role and 
responsibility. It is restricted to a particular age cohort, institutional context, and social position. Non-adult (e.g. adolescent) and non-marital (e.g. workplace) settings in which married and unmarried men and boys could, and do, exercise responsibility for reproductive health are, by default, excluded from analysis. The assumption promotes the misleading impression that men do not, or, perhaps, cannot, have reproductive responsibility for persons outside household or matrimonial circles. Yet, it is the object of common observation, if not common sense, that male responsibility is, in fact, quite regularly exercised in non-marital, pre-marital, neo-marital, post-marital, and trans-marital contexts, and that the exercise of that role varies with changes in the socioeconomic positions occupied. As a result, the conventional emphasis on male responsibility within domestic contexts alone is problematic at two levels. First, it overlooks the extensive possibilities for male responsibility for reproductive health that lie outside those contexts and, second, this emphasis intensifies female disempowerment at the domestic level.

\section{The Problem of Male Role and Responsibility}

In this paper, we argue that male role in reproductive health is more variable than how it has been conventionally and conveniently conceived. Men occupy multiple social positions and, through the life course, occupy multiple social roles, which have reproductive consequences. They are not merely husbands or fathers, but workers and co-workers, brothers, and cousins, uncles, and mentors, heads of extended family and other kin-based organizations, heads of community based organizations (CBOs), age grade leaders, religious leaders, traditional rulers, opinion leaders, school teachers, politicians, policy makers, parliamentarians, corporation chiefs, business executives, friends and associates, employers and employees, and so on. In these contrasting and mutually reinforcing positions, there are unique opportunities and contexts for the exercise of responsibility for reproductive health in both the private and public domain.

This explains why:

Compelling sociological and institutional factors exist favouring African men in matters affecting marital and family life. Men play an important role as heads of households, they are custodians of the interests of their lineage and protectors and providers of their families, and they are, therefore, the ones who make the majority of decisions pertaining to family life and the society in general [Emphases added] (Isiugo-Abanihe, 1994: 1).

This broad perspective is lacking in many conceptualizations of male role. Once the domestic context is impaired by negative financial factors that stem from a regressive economy, it is assumed that whatever impact that has on 
male role in that context is universally definitive. Our view is that further discussion of male role and responsibility should encompass the multiple roles men play on account of the variety of positions they, like women and children, occupy. Deliberate effort should be directed at understanding the generic and precise relationships between aspects of male role and an evolving moral and psychological society. How have changes in systems and relations of production affected traditional trends in which men were primarily responsible for the economic, social and medical wellbeing of their families? How have the emergent forms of men's social positions and statuses affected the performance of those roles? Have there been shifts in the system? What effects have these had on male role and responsibility for reproductive health in Africa?

Once the questions are resituated in this light, interest in the ethnographic and sociological dimensions of male responsibility for reproductive health can be traced to men's marginalization from the family planning campaigns of the 1970s, and the reproductive health movements that followed in the succeeding decades. As Nigerian maternal mortality statistics show, for instance, neither movement led to improved reproductive health benefits for the majority of women or children. These educational activities were located within antenatal clinics and targeted women who went there during pregnancy.

It was an integral part of the medicalization of family planning and reproductive health, which meant that the physical and institutional contexts in which reproductive health education was provided and received, was primarily clinical. The personnel employed (hospital employees), as well as their targets (pregnant, usually married, women), proved convenient for the obstetric establishment but was of reduced value for the real environments in which reproductive health education should be applied. In other words, viewing reproductive health from a primarily medical perspective, and delivering reproductive education without a focus on reproductive socialization, isolated the campaign from the real human and political contexts in which reproductive health education would be put into practice. It fostered male alienation and made the failure of the campaign nearly predictable.

The result was that, sub-Saharan African women received reproductive health education mostly in antenatal facilities, which men did not attend for a variety of gender and other cultural reasons. The women were thus equipped and empowered with information that their men did not have. Because this threatened the pre-existing state of domestic power relations, the women were exposed to new tensions at the matrimonial level, as they struggled to exercise autonomy and control over their bodies through covert contraception, in the face of male resistance, and, sometimes, hostility.

This was the predominant reason behind the establishment of the Male Responsibility for Reproductive Health Project (MRP) in Ugep, southern Nigeria, from 1996-2000, in which we both served as Advisor and Principal 
Investigator, respectively. The project established unequivocally that the most effective and acceptable media for the transmission of reproductive knowledge and empowerment were the ordinary traditional structures that would have been deployed if the campaigns were not externally imposed. Thus, MRP trained age grade leaders (AGLs) and entrusted them with the weekly transmission of the requirement information to their members (Obono, 2000).

The findings of MRP confirmed existing opinion that the feminization of new reproductive knowledge was threatening to men individually and capable of disrupting the entire framework of the male supremacy complex. As the MRP Report observed, "men feel marginalized from the family planning process and therefore hold the knowledge women acquire from the maternity centres as potentially disruptive of social order" (Obono, 2000: 8). If it spread, then the patriarchal order would come to an end. Male resistance to female use of contraception at the initial phases of programme intervention was the expression of male marginalization from the organizational processes and procedures of formal reproductive education. In a bid to remain the protectors of social order, men became the antagonists of the very means by which its prosperity could be assured.

It was a reaction that was highly visceral and inevitable. By excluding men from the groups that would be direct, active and participant beneficiaries of reproductive re-education, the family planning programmes constituted a real systemic threat to established norms regarding the management and use of new information of a sensitive, intimate kind. It blocked cooperation from the main decisions makers of male supremacist Africa. While the programme posed an effective challenge to that moral order by calling its sexist predilections into question, its procedures made the enlistment of male support considerably tenuous. It overlooked the reality that, in a pronatalist moral economy, nonconsultation with the decision makers over the most fundamental functional prerequisite of all, namely that of continuous biological recruitment of new members of society, was a programmatic recipe for non-cooperation. Male resistance was thus the dialectical exercise of male responsibility for preserving social stability and protecting the system from threats to its cohesion.

In this, the patriarchal orientations of most African communities are clear. A Nigerian case study showed that "the socialization process makes Nigerian men influential and dominant in all spheres of life, giving them the final say on various family issues. They are at the centre of decision-making in the traditional political economy and are important agents of change. Therefore, any successful attempt at social engineering must begin with men" (IsiugoAbanihe, 2003: 133). Perhaps the argument is made too forcefully in that instance in that it unintentionally comes across as reinforcement for sexism but the observation it makes that men are socialized to assume responsibility in multiple contexts is significant for the argument presented in this commentary. 


\section{On the Assumption of Patriarchal Treachery}

The progress of reproductive re-education would have been less tenuous if men had been involved right from the start, at these various levels. That is,

With respect to the home, men should be well informed on the reproductive process and responsible parenthood so that they can positively impact the lives of their wives and children. Since Nigerian men desire more children than women, the success of family planning and safe motherhood programmes in particular depends on male cooperation and involvement....Also, fertility transition in Nigerian men could be accelerated if government and non-governmental organizations would recognize the role and responsibility of men and bring them into the mainstream of relevant agenda (Isiugo-Abanihe, 2003: 133-4).

That is the crucial point. The formal styles and pedagogies adopted in highly clinical settings, during wives' pregnancies, by hospital personnel, alienated men, who are central decision makers of sub-Saharan African society, at home and in the society at large. The process was not integrated with existing channels of communication and control. Indeed, the social marketing of contraception on the whole could not have promoted male cooperation at these early stages.

Women were the programme's targets. The pedagogical packaging of the reproductive health material did not promote gender cooperation. It instead took the hostility of male reproductive partners for granted. It encouraged women to believe that they were in a no-win situation - one in which patriarchal treachery was not in doubt - and it was foolhardy for women to trust in the cooperation or intentions of their male partners.

For the men, who were not the programme's targets, on the other hand, the process intensified feelings of alienation, and predisposed them to attitudes of non-compliance because the supply of new knowledge that the women received threatened the patriarchal status quo and the gender relations of authority that it gave rise to. The basis of patriarchal social order (namely, male monopoly over reproductive knowledge and management) was upset by independent female acquisition of new knowledge.

The sexes parted ways, becoming mutually suspicious and mutually antagonistic. The system and structures that might have fostered equality and cooperation came to symbolize that antagonism over questions of reproductive health. It intensified pre-existing divisiveness and made it explicit at a more complicated reproductive realm. Against this background, the programmatic idea of introducing (or enforcing) male responsibility for reproductive health, or defining a role for men in this regard, contains at least three fallacies. 
1. Fundamentally, it presupposes that African men are not playing a role in safeguarding health for themselves, their partners and children. In this sense, it regards the achievement of defining that role as a movement away from a more basic background of male indifference, and is, thus, based on the fallacious idea that effective male role and responsibility for reproductive health in Africa involves a break with its past, or some form of discontinuity in the moral status quo.

2. Furthermore, it promotes the misleading idea that male resistance to women's reproductive empowerment evinces a continuation of the fundamental irresponsibility that is a part of that status quo, which must be called out of order. In this sense, the assumption is that, were African men more responsible, they would support their partners without question; and

3. Finally, it assumes that male role and responsibility for reproductive health can be sustained in the long run, even if it occurred as a de facto imposition, without dialogue with men, and without an attempt to examine how the prescribed role fits into a dynamic social world in which the integration and dislodgment of men and mores is a major challenge to the cultural system.

Together, these assumptions have shaped the discourse of male responsibility for reproductive health in Africa, as though it were the reproductive counterpoint to male corruption in governance discourse. They underlie numerous misconceptions that are published as substantiated fact about the reproductive recalcitrance of the African male. They overlook the fact that "The modern consensus is that Africa is a diverse and variable cultural enactment, not a single social entity" (Obono, 2010: 1), and, therefore, manifestations of patriarchy will vary from place to place. We argue here that the factors militating against the institutionalization of long-term reproductive health benefits for women are rooted in such programmatic assumptions as these as well as a series of other empirically defective premises for programme design and implementation. Authentic ethnographic information on African patriarchy is misinterpreted or ignored, its ramifications into the manifest responsibility men have for the well-being of their families is not granted adequate attention.

This perpetuates false negative stereotypes of the African man, which are not borne out by even a cursory familiarity with the African moral impulse, whether patriarchal or otherwise. These stereotypes transfer blame for the reproductive crisis from historical macrosystemic dislodgements in the colonial and neocolonial political economy to the micro level, where the rural and urban poor are unable to safeguard health for themselves, their partners and children in terms of the new nexuses for health procurement. As we show below, what is usually indicated as irresponsibility (or the absence of responsibility) is the 
genuine outcome of a basic male disempowerment in economic relations that came into existence with the forced incorporation of African economies and polities into the modern global market system.

\section{The Dislodgement of Male Responsibility for Reproductive Health}

Sociologically speaking, the concept of social role refers to "socially defined expectations that a person in a given social position follows" (Giddens, 2001: 28-9). It is of key social scientific significance because it foregrounds the expectations attached to given statuses in society. Roles are normative and borne out of the ideas that people have concerning propriety identified with positions occupied by individuals in society. The role of men in safeguarding reproductive health for themselves and their communities is a function of gender differences in the communities and the patriarchal ideologies that produce them. Male role can, as such, be understood as shorthand for identifying the different statuses occupied by men as they move through the life course, acquiring higher or lower degrees of access to resources (such as information, financial capacity, political positioning, and so on), although the phrase is more frequently used to designate the normative expectations attached to men's social positions as husbands.

Social roles are linked to acts, which in conjunction with several other elements constitute social situations. Patterns emerge over time in these situations and produce structures in terms of which behaviour can be understood, explained, predicted and, sometimes, controlled. Accordingly, roles are prescriptive to the extent that they have normative expectations attached to them. If a role were not prescriptive in that sense, then it would be no role at all. It is this normative dimension that constitutes acts predicated upon roles into responsible behaviour. If they matched the expectations, they constituted responsible acts; if they did not, they could be described as not responsible, or irresponsible in an outright sort of way. Against this background, male responsibility in reproductive health deals with men's conduct as it conduces with the normative expectations that members of society have with respect to the preservation of health in the domestic circle, and particularly within spousal contexts. Framed in this way, the discourse of male role and responsibility in reproductive health generates several questions.

Who determines what is appropriate at given points in time; how; why, and with what results? Who is a responsible man? By what attributes can he be identified? How do the corresponding prescriptions and proscriptions change over time? While the concept of "role" might appear to be neutral enough, the framework of "responsibility" carries with it the value-laden connotation and a psychological charge that those who are not responsible are to that degree irresponsible. It expresses the existence of underlying interests, which 
naturally lead to an interrogation of patriarchal premises of behaviour in their interface with political economy.

If we grant that men recognized and lived up their role as protectors of their health and that of their partners and children, as the preceding section posited, within what contexts does the contemporary discourse of "male responsibility" emerge? Why would we discuss "male responsibility" if we did not ascribe (or intend to ascribe) elements of irresponsibility to the conduct of the men being reviewed? What led to changes in the situation if we agree that these men were not always that way? What was the status of African male behaviour and conduct vis-à-vis reproductive health in the pre-Cairo eras that preceded its rise as main topics in global health and medicine? What did men to safeguard reproductive health for themselves, their partners and children in those periods, and why did they stop doing it?

Indigenous colonial literature is instructive in this regard. It demonstrates quite categorically that, prior to the advent of modern biomedicine (and the free market economy that came with it), men were active custodians of domestic healthcare. In Chinua Achebe's epic Things Fall Apart,

Okonkwo returned from the bush carrying on his left shoulder a large bundle of grasses and leaves, roots and barks of medicinal trees and shrubs. He went into Ekwefi's [his wife's] hut, put down his load and sat down. "Get me a pot," he said, "and leave the child [his daughter] alone." Ekwefi went to bring the pot and Okonkwo selected the best from his bundle, in their due proportions, and cut them up. He put them in the pot and Ekwefi poured in some water...She set the pot on fire and Okonkwo took up his matchet to return to his obi. "You must watch the pot carefully," he said as he went, "and don't allow it to boil over. If it does its power will be gone".... Okonkwo returned when he felt the medicine had cooked long enough. He looked it over and said it was done. "Bring a low stool for Ezinma [his sick daughter]," he said, "and a thick mat." He took down the pot from the fire and placed it in front of the stool. He then roused Ezinma and placed her on the stool, astride the steaming pot" (Achebe, 1958: 60).

This lengthy excerpt from one of Nigeria's best known writers demonstrates that, despite the depiction of Okonkwo as a male patriarch in the story, he took personal responsibility for treating his daughter's fever. Indeed, the ability of a man to provide for one's family was a core indigenous value. One's worth was measured partly in terms of the ability to live up to this expectation. This kind of role was extended to matters also of familial spiritual and economic health.

Ordinarily, the transmission of ethnomedical knowledge followed patrilineal principles. But it was shrouded in secrecy, which is arguably the bane of the development of African medicine. This need to keep things hidden 
was complemented by the fact that the practice of ethnomedicine involved elements of danger. The trees from which roots, barks, and leaves were obtained grew deep in forests and the practitioner may have to remain in these forests for days and nights on end before either the requisite revelations came to him or the required trees and herbs were located. Male heads of households regularly undertook this responsibility, and sometimes combined it with the male role of hunting.

The practice of ethnomedicine at the lineage level supported a communitywide class of male professional ethnomedical practical healers. A 10 percent sample of Nigeria's 389 ethnic groups shows that the indigenous word for healer was, in every case, masculine. That is, although women played an important role in providing obstetric and other health services to the community, there was gender cooperation in traditional society. This form of cooperation is indicated in the passage quoted above. Earlier, when Ekwefi had discovered her daughter shivering, it was to her husband that she ran, announcing "Ezinma is dying," whereupon "Okonkwo sprang from his bed, pushed back the bolt on his door and ran into Ekwefi's hut" (Achebe, 1958: 53). This alacrity itself sprang from Okonkwo's recognition of his role as health provider in the indigenous value system.

In some theocratic societies in Nigeria, of which men were the main chieftains and priests, the religious belief system developed in response to the problem of female infertility and other reproductive health complications. The position of a UNFPA report is instructive:

Men are more concerned about their partners, spouses and children than the stereotypes would suggest...the assumption of many healthcare providers that men are uninterested in taking responsibility for family planning has become a self-fulfilling prophecy. Most reproductive health/family planning service delivery systems are almost entirely oriented to women and provide little or no information about male contraceptive methods. Health workers are sometimes poorly trained in counselling men about safer sexual practices and male methods, and may communicate negative rumours about them (UNFPA, 1995: 1-2).

According to the MRP Report, men are willing and able to accept responsibility for safeguarding health for themselves, their partners and children if they are taken into confidence (Obono, 2000: 8). The reason most men do not discuss family planning with their wives may not be because they do not care, but rather because most men see reproductive decision-making as their exclusive right. In other words, the issue is not up for debate since its moral and gender parameters are clear. Nevertheless, "[although there is] widespread recognition that men need better information and health 
services...the political will to translate advocacy into action has so far been seriously absent" (Obono, 2003: 55). The general trend is to proceed as though men did not require clinical services, across different ages.

The roots of male resistance lie deep in these contexts of marginalization and the implications that the power structures of patriarchy and "the hegemonic interests and a power structure of incentives which encourage governments to adopt initiatives to modify ... local systems in accordance with neoliberal principles" (Obono, 2008: 233). This is a major reason for the tenuous implementation of antinatalist policies in the sub-region. Men were sidelined in the sensitization and mobilization processes that preceded policy formulation. The instrumental approach adopted by the State at the policy level overlooked the well-documented ethnographic fact that female reproductive behaviour in sub-Saharan Africa reflected male reproductive motivation; it did not sufficiently contend with the fact that "the characteristic male-dominant and patrilineal traditions support large family size and...men's reproductive motivation, to a large extent, affects the reproductive behaviour of their wives" (Isiugo-Abanihe, 1994: 149).

Without doubt, the family planning campaign had the manifest and latent effects of empowering women, but, through its primary emphasis on women, the campaign partly misdirected itself. It ignored "the influence of patriarchal structures on women's fertility and overlooked the fact that women managed, or mismanaged, their reproductive lives within the context of a maledominated society" (Obono, 2003: 108). The same restrictive medicalization of reproductive health education, which alienated men from the reproductive health campaigns on the basis of gender, had the effect of discriminating against adolescents on the basis of age and marital status. In this regard, the present concern in this paper with male role and responsibility for reproductive health arises within the same interventionist conditions that made the reproductive health of sub-Saharan African adolescents a leading social problem, although a corresponding amount of funding and attention as has been channelled towards adolescents is yet to be directed at rectifying this imbalance among men.

\section{Conclusion}

The presumed absence of male responsibility for reproductive health, as indicated in the reproductive health literature, does not take cognizance of the transition from anecdotal states of responsibility we provided by reference to indigenous colonial literature and the reasons for which we find it necessary to resituate the discourse within an appropriate framework in political economy. This explanation is what we advance in this paper as a theory of dislodgement.

There was no standard or uniform role for men in the Nigerian family because there were variations in family types in the country, even within the same ethnic group. Moreover, the way one defines what constitutes 
"responsibility" varies with the emphasis of that definition. There are areas of social interaction in which men misused their dominant status in the society, but there were other contexts in which their conduct was self-sacrificial and heroic. The masculinization of irresponsibility in this regard is derived from the tendency, as noted, to retain ideas of male role chiefly within familial contexts and not beyond it. In the process, however, it neglected the position (and role) of men as fathers, which involves counselling adolescents and children on reproductive health issues. It also neglected the broader role of men as members and leaders of communities, which have survived for centuries without undue external ideological interference. For these reasons, we consider that male role and responsibility in reproductive health is decomposable into the distinct competencies men occupy through the life course.

Men were at the main decision makers in traditional society. However, as the economic and political system underwent changes with the forced incorporation of the rural economies into the international labour market, working class poverty was created, and the roles and responsibility of men in Nigerian family life were transformed. As the mode of production changed, so did the relations of production. The new realignments of the family and the emergent global political economy held implications for spousal relations, and these transformations impacted negatively on all other relations within the family.

With the incorporation of African societies into the global market economy, a poor class was created and the economy of health underwent transformation. The result was that the former contexts in which men served the health needs of their families was no longer tenable. The means of accessing that resource was not accessible to significant proportions of the population. Moreover, the children of these men were beneficiaries of Western education, and would not, for that reason, readily consent to a father's diligent excursion to the bush to bring back grasses, leaves, and shrubs as an adequate response to his children's ailment.

As such, the man was incapable of catering to the health needs of his family because he lacked the financial wherewithal to do so. He was required to produce more money than was always (or ever) possible or available. His inherited ethnomedical skills had become irrelevant in the modern context. The intended beneficiaries were no longer convinced of its potency on account of the Western education they had received. Thus, the whole subject of male responsibility emanates from a faulty interpretation of systemic male disempowerment. What was in fact the result of an inability has been taken to constitute irresponsibility. Men were dislodged from the social situations in which they previously accepted and exercised responsibility for the preservation of health both at the family level, and in the community at large.

Monetary payment has become the new nexus for the procurement of modern health. The emergence of a poor class within the colonial economy 
means that that class is incapable of procuring the benefits of the commercialized health services, which that system promoted. With the growing commitment of African governments to withdraw subsidy from health, the situation with regards to the exercise of reproductive health responsibility by poor men can only grow worse.

It appears logical, therefore, to propose that the campaign to involve men in family planning and reproductive health protection ought to be accompanied by poverty alleviation schemes and family support programmes that will mitigate the economic difficulties confronting men who cannot afford the rising costs of modern medical care for themselves, their partners, and their children. This would be a necessary step toward the creation of an enabling policy and programmatic environment in which men can exercise reproductive responsibility in Africa.

\section{References}

Achebe, Chinua (1958) Things Fall Apart. London: Heinemann Educational Books.

Alan Guttmacher Institute (2003) In Their Own Right: Addressing the Sexual and Reproductive Health of Men Worldwide. New York: Alan Guttmacher Institute.

Graham, Wendy J.; Ann E. Fitzmaurice; Jacqueline S. Bell and John A. Cairns (2004) "The Familial Technique for Linking Maternal Death with Poverty". Lancet vol. 363 (9402): 23-7.

Isiugo-Abanihe, Uche C. (2003) Male Role and Responsibility in Fertility and Reproductive Health in Nigeria. Ibadan: Ababa Press.

Isiugo-Abanihe, Uche C. (1994) "Reproductive Motivation and Family-Size Preferences among Nigerian Men". Studies in Family Planning, 25(3): 149-161.

Obono, Oka (2010) "The Cultural Tapestry of African Sexuality." In Oka Obono (ed.). A Tapestry of African Sexuality. Auckland Park, South Africa: Fanele Publishers. Pp. 1-12.

Obono, Oka (2008) "Ideology and the Global Context of Nigeria's Population Policies." Nigerian Journal of Economic and Social Studies, 50(2): 233254.

Obono, Oka (2003) "Cultural Diversity and Population Policy in Nigeria". Population and Development Review, vol. 29, no. 1: 103-111.

Obono, Oka M. (2000) Final Narrative Report of the Male Responsibility and Reproductive Health Project (MRP). February 1997 - January 2000. Report of a project supported by the John D. and Catherine T. MacArthur Foundation Population Programme Fund for Leadership Development (FLD). 
The Social Sciences and Reproductive Health Research Network (SSRHN) (1999) Male Responsibility in Reproductive Health Phase 1: The Construction of Manhood in Nigeria. Ibadan: SSRHN.

United Nations Population Fund (UNFPA) (1995) Male Involvement in Reproductive Health, Including Family Planning and Sexual Health. Technical Report No. 28. New York: UNFPA. 